\title{
Follow-up assessment of two cases of trichloroethylene hypersensitivity syndrome: A case report
}

\author{
YONG-SHUN HUANG ${ }^{1}$, HAN-LIN HUANG ${ }^{1,2}$, QI-FENG WU $^{1}$, LI-HUA XIA ${ }^{1}$, \\ MING HUANG ${ }^{1}$, XIN-XIANG QIU ${ }^{1}$ and SHAN-YU ZHOU ${ }^{1}$ \\ ${ }^{1}$ Department of Occupational Medicine, Guangdong Province Hospital for Occupational Disease Prevention and Treatment, \\ Guangzhou, Guangdong 510300; ${ }^{2}$ Department of Scientific Education, Guangdong Women and Children Hospital, \\ Guangzhou, Guangdong 511442, P.R. China
}

Received January 14, 2015; Accepted March 1, 2016

DOI: $10.3892 /$ etm.2016.3357

\begin{abstract}
The present study aimed to explore the stability, curability and sequelae of cases of Trichloroethylene (TCE) Hypersensitivity Syndrome (THS), and to investigate the causal allergens of THS. Two cases of THS were followed-up in the current study; both cases were healing following glucocorticoid therapy and were discharged $>10$ weeks prior to follow-up. A questionnaire investigation, health examination and patch test were performed. Allergens of TCE and its metabolites, including chloral hydrate, trichloroethanol $(\mathrm{TCOH})$ and trichloroacetic acid, were applied in the patch test; 4 controls were included. The two subjects were experiencing itching, pigmentation and xerosis of the skin, and had abnormal results in the ophthalmology Schirmer I test and tear break-up time. The body temperature, liver function, superficial lymph nodes, blood, urine routine and autoimmune antibodies of two subjects were shown to be normal, and no new rashes had appeared. All mass concentration of chloral hydrate and $\mathrm{TCOH}$ were positive; $5.0 \%$ trichloroacetic acid was weakly positive, $0.5 \%$ trichloroacetic acid and all mass concentration of TCE were negative. All patch tests were negative in the 4 control subjects. The results suggest that THS was stable following treatment with glucocorticoid therapy. Dry eye syndrome may continue as a sequelae of THS. The patch test demonstrated that the mechanism underlying THS is delayed-type hypersensitivity induced by TCE. In addition, as the hypersensitivity state in a THS rehabilitee could be sustained over a long period of time, it suggests that the metabolites of TCE, not TCE itself, are responsible for THS. Therefore, patients with THS should avoid contact with TCE
\end{abstract}

Correspondence to: Dr Han-Lin Huang, Department of Occupational Medicine, Guangdong Province Hospital for Occupational Disease Prevention and Treatment, 68 Haikang Street, Xingangxi Road, Haizhu, Guangzhou, Guangdong 510300, P.R. China

E-mail: huanghanlin_b@163.com

Key words: trichloroethylene, chloral hydrate, trichloroethanol, trichloroacetic acid, hypersensitivity syndrome, patch test and its metabolites, and avoid using hypnotic and anticonvulsive drugs containing chloral hydra as the primary ingredient.

\section{Introduction}

Trichloroethylene (TCE) is a ubiquitous chemical used occupationally for various production and manufacturing purposes; it is widely used in metal, electroplating, electronics and other industries. Since 1990, numerous patients with Trichloroethylene Hypersensitivity Syndrome (THS) were exposed to TCE; this has attracted much attention worldwide (1-3). THS was shown to occur in $1-13 \%$ of the TCE-exposed workers (3). In the Chinese prescribed occupational disease list, THS is known as occupational medicamentosa-like dermatitis induced by TCE. Concerns about THS have driven epidemiological and experimental studies investigating TCE exposure and risks associated with THS (1,4-6).

The genetic polymorphism of human leukocyte antigen HLA-B*1301 is strongly associated with THS among exposed workers (4). Although the mechanism underlying TCE toxicity remains the subject of debate, THS is suggested to be a type VI hypersensitivity (5), although types II and III hypersensitivity may also be associated with THS (7). Current treatment strategies for THS include hormonal therapy, administration of $\gamma$-globulin, protection of liver and reinforcement of skin care $(8,9)$. THS can also be treated with glucocorticoid therapy, and the primary therapeutic principle is to prescribe an appropriate dosage of glucocorticoids early in the course of the disease, followed by a tapered reduction of the dose $(8,9)$. Despite extensive research, studies are limited with regards to the stability, curability and sequelae of THS. Furthermore, the nature of the causative compound of THS was also questioned by some researchers. Therefore, by completing a follow-up assessment of two patients who had THS, the current study was designed to explore the stability, curability and sequelae of THS, and to investigate the causative compound.

\section{Materials and methods}

Subjects. The study protocol was conducted according to the principles of the Declaration of Helsinki and approved by the Medical Ethics Committee of the Guangdong Province 
Hospital for Occupational Disease Prevention and Treatment (GDOH; Guangzhou, China). The subjects provided their written informed consent.

In March 2011, 2 male subjects (age, 42 years) with healing THS, who were discharged from the GDOH $>10$ weeks prior to the commencement of the study, were included. The two cases were diagnosed with THS by three occupational dermatologists of the hospital, based on the Chinese National Diagnostic Criteria of Occupational Disease (GBZ 185-2006; Ministry of Health, China, 2006; appendix A; http://www.moh.gov. $\mathrm{cn} / \mathrm{cmsresources/zwgkzt/wsbz/new/20080118111726.pdf).} \mathrm{Four}$ patients with occupational noise-induced hearing loss, without a history of dermatosis, served as controls for the patch tests.

Questionnaire. The contents of the questionnaire questioned whether the patients suffered from a cold, as well as skin, eye or liver abnormalities. The subjects were questioned on disease, medication and occupational history.

Health examination. The subjects were hospitalized for $\sim 1$ week. During the study, the subjects underwent a series of investigations, including the following: Physical examination; ophthalmic examination; electrocardiogram; X-ray; abdominal color ultrasound (liver, kidney and spleen); liver function tests (7080 Automatic Analyzer; Hitachi, Tokyo, Japan) including the analysis of total protein, albumin, total bilirubin, direct bilirubin, indirect bilirubin, alkaline phosphatase, gamma glutamyl transferase, total bile acids, aspartate aminotransferase (AST) and alanine aminotransferase (ALT); routine blood tests (XT-1800i hematology analyzer; Sysmex Corp., Kobe, Japan); routine urinary tests (Mejer-600; Shenzhen Mejer Medical Science and Technology Co., Ltd., Shenzhen, China); autoimmune disease indicators including anti-nuclear antibody (ANA), anti-DNA antibodies and anti-double-stranded DNA (dsDNA); Schirmer I test (SIT) and tear break-up time (BUT) test. These examinations were performed on three occasions.

Patch test. TCE (purity, $\geq 99.5 \%$; Sigma-Aldrich, St. Louis, MO, USA), chloral hydra ( $\mathrm{CH}$; purity $\geq 99.5 \%$; Honeywell Specialty Chemicals Seelze GmbH, Seelze, Germany) and trichloroethanol (TCOH; purity $\geq 98.0 \%$; Sigma-Aldrich) were added to olive oil (Sigma-Aldrich), and trichloroacetic acid (TCA; purity $\geq 99.5 \%$; Tianjin Chemical Reagent Second Factory, Tianjin, China) was added to saline to prepare various concentrations of allergens. According to previous trial tests (10-14), TCE $(50,25,10$ and $5 \%$ in olive oil), chloral hydrate ( 15,10 and $5 \%$ in olive oil), TCOH $(5,0.5$ and $0.05 \%$ in olive oil) and TCA (5 and $0.5 \%$ in saline) were used in the patch test. Olive oil and normal saline served as controls. The allergen at the highest concentration was selected as the allergen in the control group, since it would induce the highest positive rate in the patch test.

The patch test method and interpretation followed the International Contact Dermatitis Research Group (ICDRG) criteria (15). Briefly, the patch test was performed as follows: Each well of the patch test apparatus (Finn chamber; Beijing Baiyi Yida Science and Technology Development Ltd., Beijing, China) was filled with $25 \mu 1$ allergen, olive oil or saline, and the apparatus was numbered and patched to the back of the subjects. The edge of the apparatus was reinforced by $3 \mathrm{M}$ micropore permeable medical tape (Minnesota Mining and Manufacturing Medical Equipment Co., Ltd., Shanghai, China). The subjects did not disturb the patch test for $48 \mathrm{~h}$; showering was forbidden during the test. The patches were removed after $48 \mathrm{~h}$. Observations and images were recorded by two occupational dermatologists of GDOH $0.5 \mathrm{~h}, 24 \mathrm{~h}$ and $48 \mathrm{~h}$ following the removal of the patch test. The results were observed, recorded and filed according to the ICDRG criteria by two professional dermatologists.

The 2 cases with THS and the 4 control subjects did not receive treatment with corticosteroids and other immunosuppressive drugs, or anti-infection drugs for 2 weeks prior to the patch test.

\section{Results}

Case one. The patient was exposed to TCE whilst working in a hardware products factory between August and September 2010. His duties included the cleaning of wax with organic solvents $(90.857 \%$ TCE). The airborne concentrations of the time-weighted average in the working place of the subject ranged between 123.38 and $171.82 \mathrm{mg} / \mathrm{m}^{3}$. The onset of THS occurred in September 2010, and the patient was transferred to the GDOH after 12 days. On admission, the body temperature of the patient was $39.8^{\circ} \mathrm{C}$. Physical examination revealed erythematous lesions over the whole body (Fig. 1). Dark erythematous lesions were present over the trunk, and the majority of the rash was confluent and resembled erythroderma. Scattered desquamated skin was also evident, the palms and soles were pigmented and hard to the touch, while the nature of the rash was similar to exfoliative dermatitis. Additionally, there was lymphadenectasis and tenderness of the submandibular, supraclavicular, inguinal and submental lymph nodes. The patient had conjunctival congestion, scleral icterus and itching of the eyes. The levels of ALT were $300 \mathrm{U} / \mathrm{l}$ (normal range, $<40 \mathrm{U} / \mathrm{l}$ ), those of AST were $133 \mathrm{U} / \mathrm{l}$ (normal range, $<40 \mathrm{U} / \mathrm{l}$ ) and the concentration of TCA in the urine was $14.10 \mathrm{mg} / \mathrm{l}$. Methylprednisolone $(500 \mathrm{mg} / \mathrm{day}$; Pfizer Manufacturing, Puurs, Belgium) was administrated intravenously, and the patient also received diammonium glycyrrhizinate (Chia Tai Tianqing Pharmaceutical Group Co., Ltd., Lianyungang, China) for the protection of the liver and stomach. On day 3 after admission, the patient's body temperature returned to normal with no further spread of the rash and liver function test results were improved. Therefore, the methylprednisolone dose was reduced to $450 \mathrm{mg} / \mathrm{day}$, and after 9 days of continued improvement, the dose was tapered to $300 \mathrm{mg} / \mathrm{day}$ and then progressively reduced by $50-150 \mathrm{mg} /$ day. The total duration and dosage of methylprednisolone treatment was 81 days and $12,028 \mathrm{mg}$, respectively. When the skin recovered, the body temperature and liver function test results returned to normal, and the patient was discharged in January 2011. The patient returned for a follow-up assessment in March 2011.

Case two. The second subject had an employment history that was similar to the first case. In September 2010, a widespread pruritic rash appeared on the patient's legs and he was transferred to GDOH for further assessment 9 days after the appearance of the rash. On admission, the body temperature of the patient was $36.8^{\circ} \mathrm{C}$. Physical examination revealed dark erythematous skin 
A

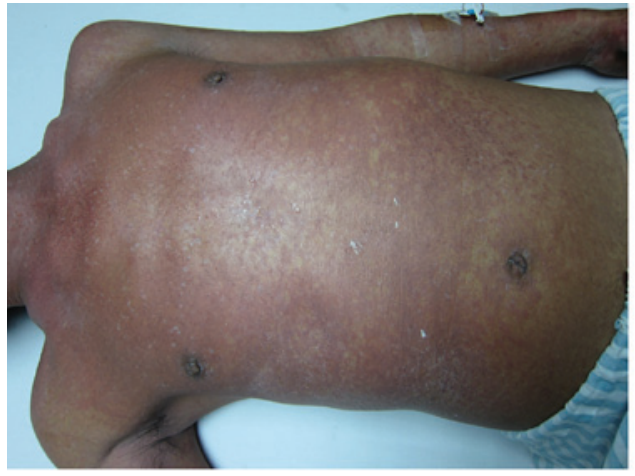

C

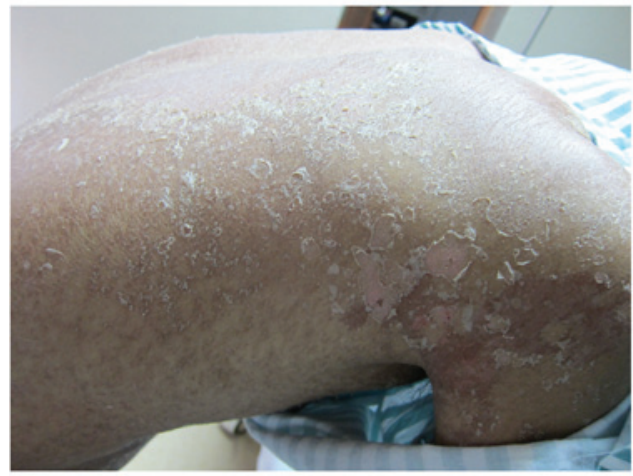

$\mathbf{E}$

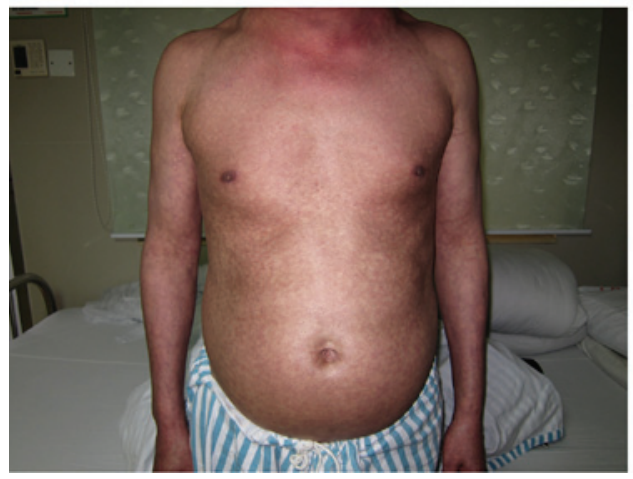

B

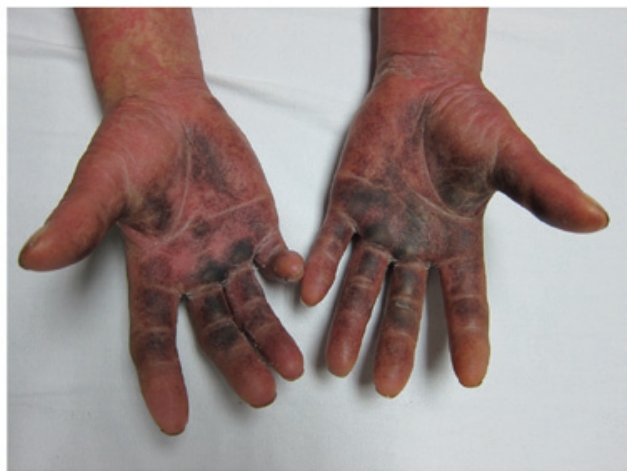

D

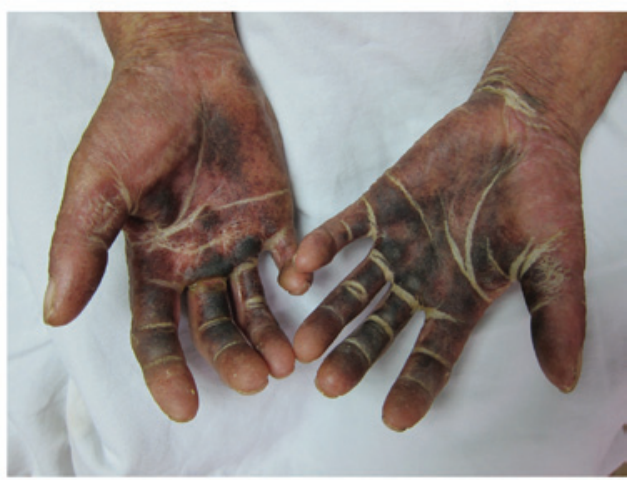

$\mathbf{F}$

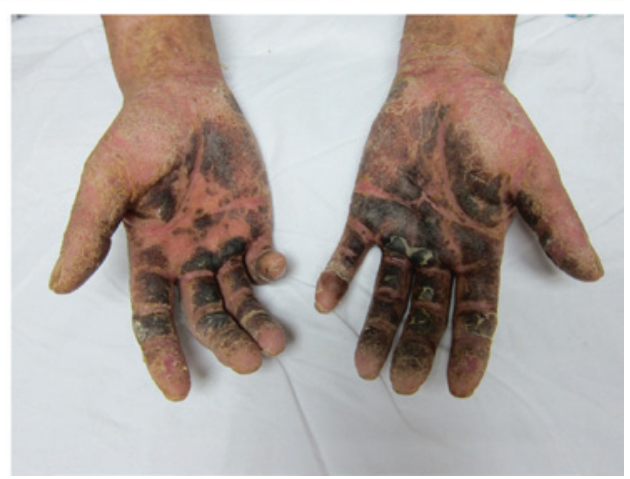

Figure 1. Case one. (A and B) The skin lesions of patient one when hospitalized at the acute stage. Dark erythematous lesions are present over the trunk. The majority of the rash was confluent and resembled erythroderma. Scattered desquamated skin was also evident. The palms and soles were pigmented and were hard to the touch. The nature of the rash was similar to exfoliative dermatitis. (C and D) The progressive stage; following treatment, the rash gradually disappeared although a large area of desquamated skin remained. The palms and soles exhibited increased pigmentation and became harder. (E and F) The healing stage; the skin disorder had recovered although pigmentation remained over the whole body. Skin was peeling on the back, palms and soles, with evidence of new skin formation.

lesions over the majority of the body (Fig. 2). The palms, fingers, soles and toes were swollen and tender, and the nature of the rash was similar to exfoliative dermatitis. Lymphadenectasis and tenderness was present in the submandibular, throat, axillary and inguinal lymph nodes. The levels of ALT were $343 \mathrm{U} / 1$ and those of AST were $153 \mathrm{U} / 1$, and the concentration of TCA in the urine was $43.34 \mathrm{mg} / \mathrm{l}$. Methylprednisolone (300 mg/day) was administrated intravenously, and the patient also received diammonium glycyrrhizinate for protection of the liver and stomach. On day 3 after admission, the results of liver function tests were improved. There was no further spread of the rash and the patient's temperature normalized. On the day 4, the methylprednisolone dose was reduced to $250 \mathrm{mg} /$ day; the patient's condition continued to improve and the dose was tapered progressively. The total duration and dosage of methylprednisolone administration was 64 days and $5,237 \mathrm{mg}$, respectively. When the skin recovered, the body temperature and liver function returned to normal, and the patient was discharged in December 2010. The patient returned for a follow-up assessment in March 2011.

\section{Follow-up assessment}

Survey findings. Skin itching and xerosis were the primary complaints of both patients; no other symptoms were reported.

Health examination findings. The body temperature of both patients was normal. Skin examination revealed that spread pigmentation, but no new rashes or lymphadenectasis were apparent. The abdominal color ultrasound (liver, kidney and spleen), electrocardiogram and X-ray did not detect any abnormal changes. The blood tests, urinary test and liver function test were normal. Autoimmune disease indicators including ANA, anti-DNA antibodies and dsDNA were negative. The SIT results for patient one were as follows: Right eye $8.0 \mathrm{~mm} / 5 \mathrm{~min}$ and left eye $18.0 \mathrm{~mm} / 5 \mathrm{~min}$; the SIT results for patient two were as follows: Right eye $2.0 \mathrm{~mm} / 5 \mathrm{~min}$ and left eye $5.0 \mathrm{~mm} / 5 \mathrm{~min}$. A normal result is $<10 \mathrm{~mm} / 5 \mathrm{~min}$. The BUT 
A

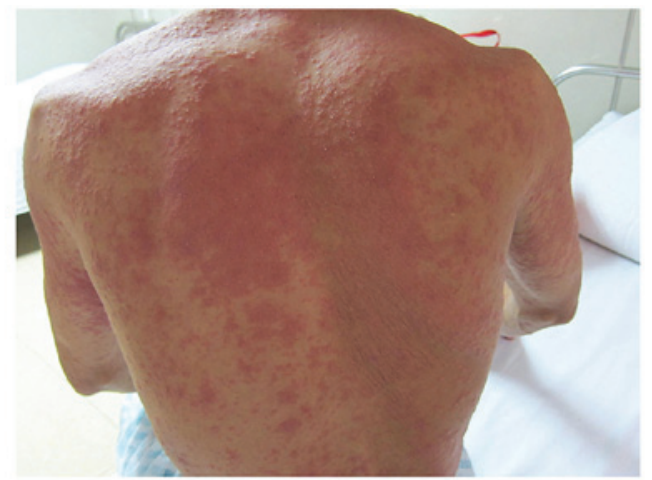

C

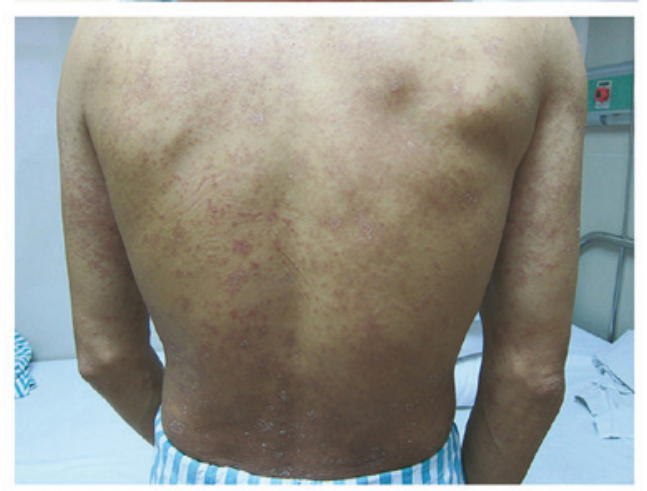

$\mathbf{E}$

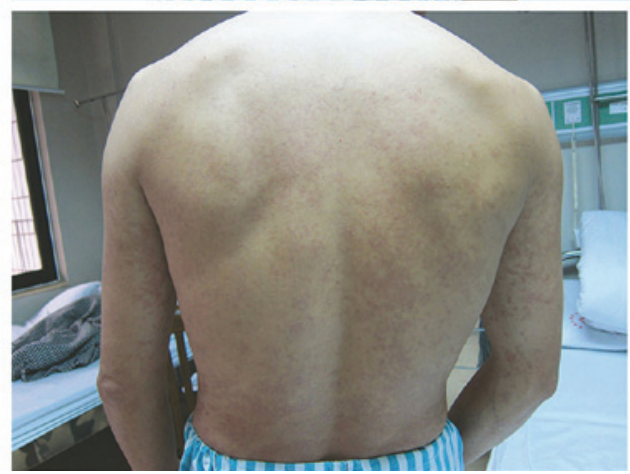

B

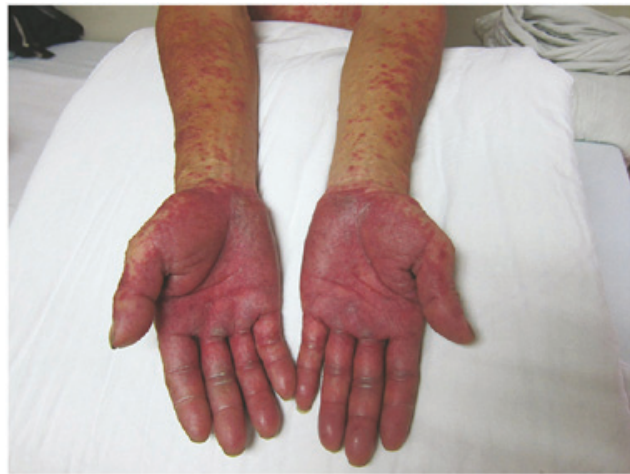

D

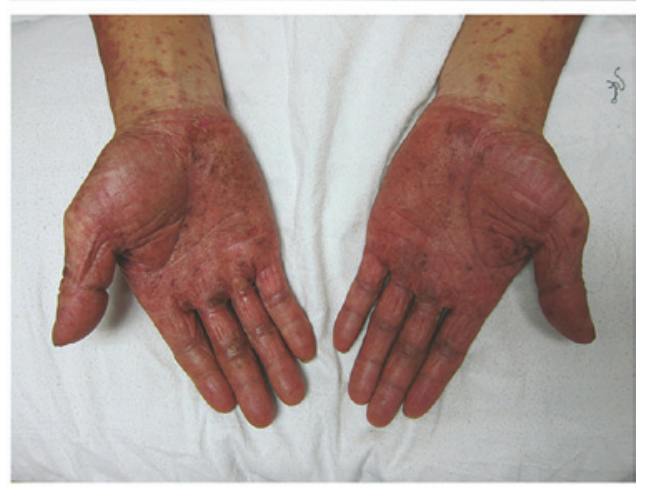

$\mathbf{F}$

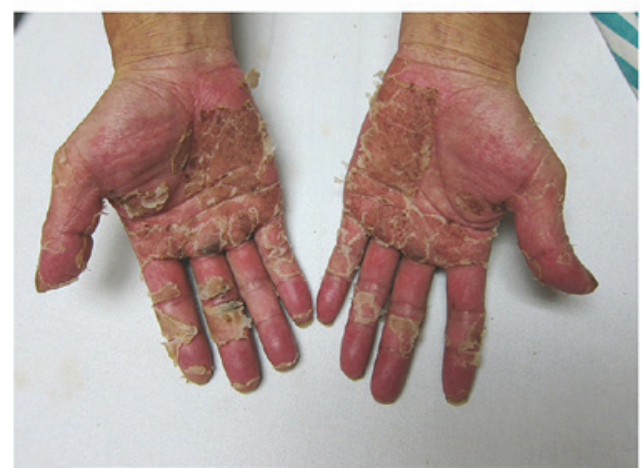

Figure 2. Case two. (A and B) The skin lesions of patient two when hospitalized at the acute stage. Dark erythematous lesions were widespread with confluent areas. The palms, fingers, soles and toes were swollen and tender. The nature of the rash was similar to exfoliative dermatitis. (C and D) The progressive stage; following treatment, the rash gradually disappeared while desquamated skin remained on some areas of the body. Skin swelling resolved and scattered pigmentation remained on the palms. (E and F) The healing stage; the skin disorder recovered although pigmentation remained over the whole body. Increased skin thickness and swelling changed to skin desquamation, with evidence of new skin formation.

results for patient one were as follows: Right eye $4.0 \mathrm{sec}$ and left eye $5.0 \mathrm{sec}$; the BUT results for patient two were as follows: Right eye $3.0 \mathrm{sec}$ and left eye $4.0 \mathrm{sec}$. A normal result is $>10 \mathrm{sec}$.

Patch test results. No adverse reactions were observed during the patch test. Patches of skin with olive oil, saline and adhesive paste did not show abnormal changes such as reddening of the skin and swelling. The patch tests were positive for all mass concentrations of $\mathrm{CH}$ and $\mathrm{TCOH}$, were weakly positive for $5.0 \%$ TCA, and were negative for $0.5 \%$ TCA and all mass concentrations of TCE. The four control patches also returned negative results. The results are presented in Table I and Fig. 3.

\section{Discussion}

In the present study, THS was caused in both patients by exposure to TCE without any previous history. To the best of our knowledge, this is the first study to describe the simultaneous THS onset in two patients that were exposed to the same work environment (same factory), and to perform follow-up assessment in THS cases. The patients presented predominantly with symptoms of skin involvement, as well as fever, lymphadenectasis and liver dysfunction $(2,3,16,17)$. The primary therapeutic principle was to prescribe an appropriate dosage of glucocorticoid early in the course of the disease, followed by a tapered dose reduction. However, it is important to protect the liver and stomach from adverse effects during the treatment of THS (9). In the present study, the symptoms of the patients markedly improved when glucocorticoid therapy was administered. Following the discharge of patients one and two for 11 and 15 weeks, respectively, health examinations demonstrated that both patients were healthy. However, skin examination revealed pigmentation, itching and xerosis, but no new rash. These results suggested that the curative effect of glucocorticoid therapy is stable and that patients do not relapse following healing.

SIT and BUT are critical dry eye tests (18). The SIT and BUT results were abnormal in both patients, suggesting that dry eye syndrome may be a sequelae for THS. It has previously 
Table I. Patch test results for TCE and its metabolites.

\begin{tabular}{|c|c|c|c|c|c|}
\hline \multirow[b]{2}{*}{ Patch test no. } & \multirow[b]{2}{*}{ Chemical and concentration } & \multicolumn{2}{|c|}{ Reactions at $48 \mathrm{~h}$} & \multicolumn{2}{|c|}{ Reactions at $72 \mathrm{~h}$} \\
\hline & & Case one & Case two & Case one & Case two \\
\hline 1 & Control (NS) & - & - & - & - \\
\hline 2 & Control (OO) & - & - & - & - \\
\hline 3 & TCA $5 \%$ in NS & + & + & + & + \\
\hline 4 & TCA $0.5 \%$ in NS & - & - & - & - \\
\hline 5 & $\mathrm{TCOH} 5 \%$ in $\mathrm{NS}$ & ++ & ++ & ++ & ++ \\
\hline 6 & TCOH $0.5 \%$ in NS & ++ & ++ & ++ & ++ \\
\hline 7 & $\mathrm{TCOH} 0.05 \%$ in NS & ++ & ++ & ++ & ++ \\
\hline 8 & $\mathrm{CH} 15 \%$ in $\mathrm{NS}$ & ++ & ++ & ++ & ++ \\
\hline 9 & $\mathrm{CH} 10 \%$ in NS & ++ & ++ & ++ & ++ \\
\hline 10 & $\mathrm{CH} 5 \%$ in NS & ++ & ++ & ++ & ++ \\
\hline 11 & TCE $50 \%$ in $\mathrm{OO}$ & - & - & - & - \\
\hline 12 & TCE $25 \%$ in $\mathrm{OO}$ & - & - & - & - \\
\hline 13 & TCE $10 \%$ in $\mathrm{OO}$ & - & - & - & - \\
\hline 14 & TCE 5\% in OO & - & - & - & - \\
\hline
\end{tabular}

TCA, TCOH, $\mathrm{CH}, \mathrm{TCE}$ had a purity of $>99 \%$. OO, olive oil; NS, normal saline; TCA, trichloroacetic acid; TCOH, trichloroethanol; $\mathrm{CH}$, chloral hydra; TCE, trichloroethylene.

A

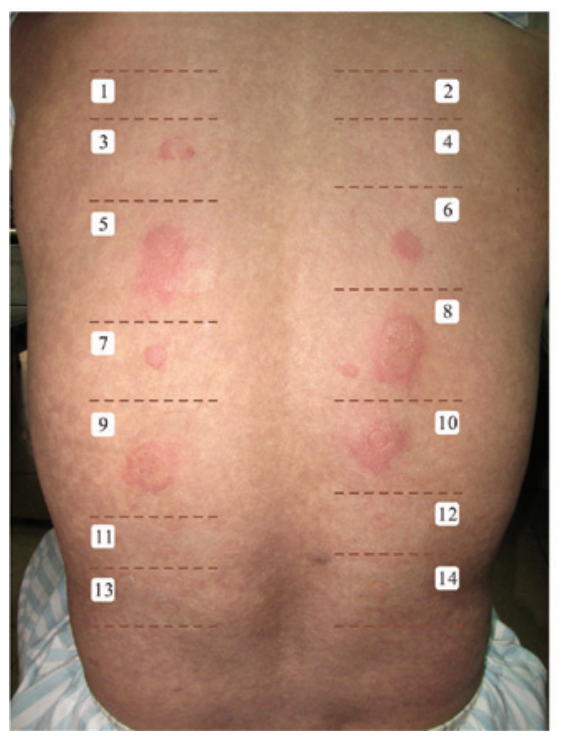

B

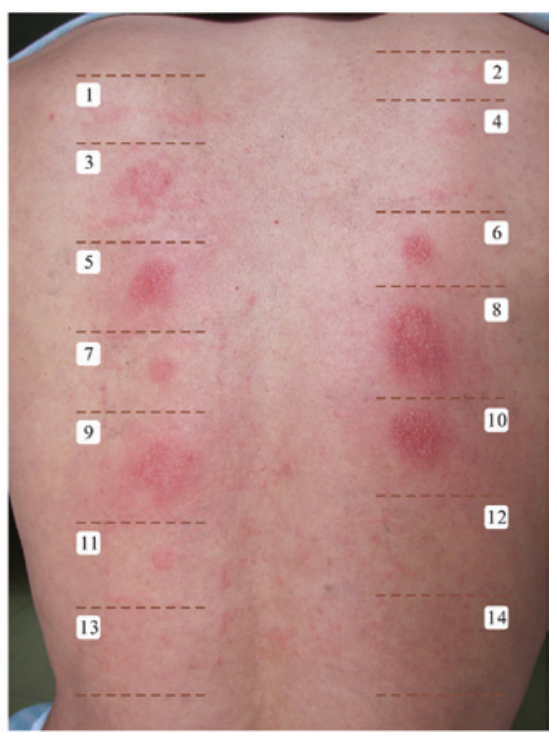

Figure 3. Patch testing results in (A) case one and (B) case two, of the chemicals mentioned in Table I. Positive reactions were observed for trichloroethanol $(5,0.5$ and $0.05 \%$ in normal saline), chloral hydrate $(15,10$ and $5 \%$ in normal saline) and trichloroacetic acid (5\% in normal saline) in both cases. However, trichlorethanol and trichloroacetic acid $(0.5 \%$ in normal saline) were negative.

been reported that Stevens-Johnson syndrome results in a lack of lacrimal gland secretion, resulting in various severe ocular surface disorders manifesting dry eye $(19,20)$. Considering that the clinical manifestations and mechanism underlying THS resemble those of Stevens-Johnson syndrome, dry eye syndrome may be one of the primary sequelae of THS; this requires further study.

TCE is predominantly metabolized by cytochrome P450 (10). Two active metabolic compounds of TCE are chloral and $\mathrm{CH}$; these metabolites have similar biological properties as the former metabolite hydrates rapidly to $\mathrm{CH}$.
$\mathrm{CH}$ is easily reduced to $\mathrm{TCOH}$ (a reversible reaction) and then to TCA (21). A patch test is now considered to be a recognized method for confirming an allergic contact dermatitis diagnosis and distinguishing the causal allergen(s), as well as identifying a type IV (cell delayed) hypersensitivity reaction (22-24). In the present study, the patch test was positive for $\mathrm{CH}, \mathrm{TCOH}$ and TCA, but negative for all mass concentrations of TCE, in both patients, results which were consistent with those of previous investigations $(11-14,16,25)$. This suggested that the causal allergens for THS were metabolites of TCE, not TCE itself; it can be hypothesized that the mechanism underlying 
THS is cell delayed-type hypersensitivity induced by TCE exposure.

It has been reported that THS patients may relapse following re-exposure to TCE (8). The patch test was positive for $\mathrm{CH}$, TCOH and TCA following healing for $>10$ weeks, illustrating that the hypersensitivity state in patients who had THS may be sustainable over a long period of time. Therefore, in order to avoid a relapse, patients who previously had THS should be advised to avoid re-exposing themselves to TCE and its metabolites. However, as the study period was short in the follow-up assessment in the present study, the sustainable period of hypersensitivity state remains unclear.

In conclusion, the follow-up assessment in the current study suggested that THS does not recur following healing, and that the curative effect of glucocorticoid therapy is stable; however, the results suggested that dry eye syndrome may continue as sequelae for THS. The mechanism underlying THS may be cell delayed-type hypersensitivity induced by TCE exposure; the fact that the hypersensitivity state in patients with THS remained over a long period of time indicates that the causal allergens for THS were the metabolites of TCE. Therefore, it can be suggested that patients who previously had THS do not re-expose themselves to TCE and its metabolites, and avoid receiving antipyretic, hypnotic or anticonvulsive medicines in which $\mathrm{CH}$ is a primary ingredient. Due to the sample and follow-up period limitations in the present study, further studies are required to verify these conclusions.

\section{Acknowledgements}

The authors are grateful to Dr. Jianxun Huang and Dr. Zhenlie Huang for their help with the present study. The study was supported by the Guangdong Provincial Key Laboratory of Occupational Disease Prevention and Treatment (grant no. 2012A061400007), the National Key Technologies R\&D Program of China during the 12th Five-Year Plan Period (grant no. 2014BAI12B01) and National Natural Science Foundation of China (grant no. 81502769).

\section{References}

1. Huang Z, Yue F, Yang X, Xia L, Chen C, Qiu X, Huang J, Li L, Kamijima M, Nakajima T and Huang H: Upregulation of calprotectin and downregulation of retinol binding protein in the serum of workers with trichloroethylene-induced hypersensitivity dermatitis. J Occup Health 54: 299-309, 2012.

2. Xu X, Yang R, Wu N, Zhong P, Ke Y, Zhou L, Yuan J, Li G, Huang $\mathrm{H}$ and $\mathrm{Wu} \mathrm{B}$ : Severe hypersensitivity dermatitis and liver dysfunction induced by occupational exposure to trichloroethylene. Ind Health 47: 107-112, 2009.

3. Kamijima M, Hisanaga N, Wang $\mathrm{H}$ and Nakajima T: Occupational trichloroethylene exposure as a cause of idiosyncratic generalized skin disorders and accompanying hepatitis similar to drug hypersensitivities. Int Arch Occup Environ Health 80: 357-370, 2007.

4. Li H, Dai Y, Huang H, Li L, Leng S, Cheng J, Niu Y, Duan H, Liu Q, Zhang X, et al: HLA-B*1301 as a biomarker for genetic susceptibility to hypersensitivity dermatitis induced by trichloroethylene among workers in China. Environ Health Perspect 115: 1553-1556, 2007.

5. Tang X, Que B, Song X, Li S, Yang X, Wang H, Huang H, Kamijima M, Nakajima T, Lin Y and Li L: Characterization of liver injury associated with hypersensitive skin reactions induced by trichloroethylene in the guinea pig maximization test. J Occup Health 50: 114-121, 2008.
6. Kamijima M, Wang H, Yamanoshita O, Ito Y, Xia L, Yanagiba Y, Chen C, Okamura A, Huang Z, Qiu X, et al: Occupational trichloroethylene hypersensitivity syndrome: Human herpesvirus 6 reactivation and rash phenotypes. J Dermatol Sci 72: 218-224, 2013.

7. Zhao N, Wang HL, Yue F, Zeng ZM, Li HL, Huang YS and Chen RT: Studying the changes of the related serum complement immune indexes in patients with occupational medicamentosa-like dermatitis induced by trichloroethylene and workers occupationally exposed to trichloroethylene. Zhonghua Lao Dong Wei Sheng Zhi Ye Bing Za Zhi 30: 284-288, 2012 (In Chinese).

8. Liu J: Clinical analysis of seven cases of trichloroethylene medicamentose-like dermatitis. Ind Health 47: 685-688, 2009.

9. Xia LH, Huang HL, Kuang SR, Liu HF and Kong LZ: A clinical analysis of 50 cases of medicament-like dermatitis due to trichloroethylene. Zhonghua Lao Dong Wei Sheng Zhi Ye Bing Za Zhi 22: 207-210, 2004 (In Chinese).

10. Chiu WA, Jinot J, Scott CS, Makris SL, Cooper GS, Dzubow RC, Bale AS, Evans MV, Guyton KZ, Keshava N, et al: Human health effects of trichloroethylene: Key findings and scientific issues. Environ Health Perspect 121: 303-311, 2013.

11. Chae H, Lee S, Lee K, Kim J, Lee S, Shin D, et al: Exfoliative dermatitis and toxic hepatitis associated with occupational exposure to trichloroethylene. Korean J Occup Environ Med 15: 111-117, 2003 (In Korean).

12. Chittasobhaktra T, Wannanukul W, Wattanakrai P, Pramoolsinsap C, Sohonslitdsuk A and Nitiyanant P: Fever, skin rash, jaundice and lymphadenopathy after trichloroethylene exposure: A case report. J Med Assoc Thai 80 (Suppl 1): S144-S148, 1997.

13. Phoon WH, Chan MO, Rajan VS, Tan KJ, Thirumoorthy T and Goh CL: Stevens-Johnson syndrome associated with occupational exposure to trichloroethylene. Contact Dermatitis 10: 270-276, 1984.

14. Conde-Salazar L, Guimaraens D, Romero LV and Sanchez Yus E: Subcorneal pustular eruption and erythema from occupational exposure to trichloroethylene. Contact Dermatitis 9: 235-237, 1983.

15. Ohtoshi S, Kitami Y, Sueki H and Nakada T: Utility of patch testing for patients with drug eruption. Clin Exp Dermatol 39: 279-283, 2014.

16. Huang $\mathrm{Y}$ and Huang $\mathrm{H}$ : Research progress oil immune injury resulted from occupational medicamentose-like dermatitis induced by trichloroethylene. Zhong Guo Zhi Ye Yi Xue 37: 157-162, 2010 (In Chinese).

17. Huang H, Kamijima M, Wang H, Li S, Yoshikawa T, Lai G, Huang Z, Liu H, Chen J, Takeuchi Y, et al: Human herpesvirus 6 reactivation in trichloroethylene-exposed workers suffering from generalized skin disorders accompanied by hepatic dysfunction. J Occup Health 48: 417-423, 2006.

18. Wu H, Wang Y, Dong N, Yang F, Lin Z, Shang X and Li C: Meibomian gland dysfunction determines the severity of the dry eye conditions in visual display terminal workers. PLoS One 9: e105575, 2014.

19. Schrader S, Liu L, Kasper K and Geerling G: Generation of two- and three-dimensional lacrimal gland constructs. Dev Ophthalmol 45: 49-56, 2010.

20. Dong N, Li W, Lin H, Wu H, Li C, Chen W, Qin W, Quyang L, Wang $\mathrm{H}$ and Liu Z: Abnormal epithelial differentiation and tear film alteration in pinguecula. Invest Ophthalmol Vis Sci 50: 2710-2715, 2009.

21. Lash LH, Fisher JW, Lipscomb JC and Parker JC: Metabolism of trichloroethylene. Environ Health Perspect 108 Suppl 2: 177-200, 2000.

22. Gawkrodger DJ: Patch testing in occupational dermatology. Occup Environ Med 58: 823-828, 2001.

23. Shear NH, Milpied B, Bruynzeel DP and Phillips EJ: A review of drug patch testing and implications for HIV clinicians. AIDS 22: 999-1007, 2008.

24. Slodownik D, Williams J, Frowen K, Palmer A, Matheson M and Nixon R: The additive value of patch testing with patients' own products at an occupational dermatology clinic. Contact Dermatitis 61: 231-235, 2009.

25. Watanabe H, Tohyama M, Kamijima M, Nakajima T, Yoshida T, Hashimoto K and Iijima M: Occupational trichloroethylene hypersensitivity syndrome with human herpesvirus- 6 and cytomegalovirus reactivation. Dermatology 221: 17-22, 2010. 